when another major European country (Germany) is, at last, beginning to reform its higher education system by granting greater autonomy to institutions, introducing tuition fees, and funding Io of its universities as elites to compete with Oxford, Cambridge, and the US Ivy League. Life in the top echelon of globalized higher education is not going to get any less competitive (not least as China's universities develop), and the best chance of survival lies in being as free as possible from the dead hand of government interference in pricing the product-a freedom, however, that rightly demands in return that Oxford remains an open and accessible academic meritocracy.

Author's note: This article is a short version of the author's chapter in Hugo de Bergh, Jeremy Black, and Anna F. Fazackerley, eds., Can the Prizes Still Glitter: The Future of British Universities in the Changing World (2007). See www.agora-education.org.

\section{Mass Higher Education and the Super Research University}

\section{DAVID P. BAKER}

David P. Baker is professor of education and sociology at the Pennsylvania State University, Department of Education Policy Studies. He was a 2005/06 Fulbright New Century Scholar. Address: Department of Education Policy Studies, Pennsylvania State University, Rackley Building, University Park, PA, 16801, USA. E-mail: dpb4@psu.edu.

W orldwide, two major transformations in higher education are simultaneously under way. Many scholarly and media accounts of these two changes present them as polar opposites, creating more conflict than harmony within the university. The first trend, often considered pedestrian, is the unprecedented expansion and massification of higher education in most nations, not only in wealthy nations such as the United States. This expansion follows an educational revolution that has already seen enrollment rates in elementary and secondary schooling skyrocket over the past 60 years. The second trend is the rise and flourishing of what can be called the "super research university," mostly in the United States but increasingly now a model aspired to by many research universities throughout the world.

Counter to the usual assumption of a conflicting relationship between these two trends, at their roots they are actually so symbiotic that each would likely not be happening if not for the other. Recent analysis of both the expansion of education and the growth of the super research university indicates that mass enrollments and completion of higher education lead the way toward greater societal support for a larger and wealthier higher education system that can include the expensive super research universities.

\section{Mass Higher Education}

Only a few decades ago as wealthy nations were completing expanded secondary schooling, many pundits predicted either a death of educational expansion at the university's gate or even a social crisis because of too much expansion of higher education. Instead, higher education ascended into rapid expansion. In the United States, for example, every decade sees a substantially larger proportion of students going on to higher education. For example, the National Center for Education Statistics recently reported that the percentage of all high school graduates enrolling in higher education increased from 49 percent in I972 to 69 percent in 2005 , and completions of the bachelor of arts and associate in science degrees grew by 33 percent and 46 percent, respectively, from 1989 to 2004 . At even a faster rate similar growth is occurring worldwide, where currently around a fourth of all youth enroll in higher education, a nearly Io-fold increase since the middle of the 2 oth century.

Schooling everyone across the lifespan is a truly revolutionary idea in the development of human society with substantial implications for how we think, work, and live. This idea has become so incorporated into modern culture that mass higher education, often thought of in the past as a mere fantasy, is rapidly spreading across the world.

\section{The American Super Research University}

The advent of the super research university in the United States over the past several decades is an equally stunning educational development. The small but growing number of these institutions are able to produce unprecedented levels of science, technology, and knowledge about human society. In spite of the unprecedented founding and recurring expenses, these institutions continue to expand and increase in the United States. However, other wealthy nations, such as Germany, are having a difficult time producing even one such university.

The model for the American super research university has become attractive to many other nations. From this model, policymakers identify factors to mimic-including faculty working conditions, competitiveness-based governmental support for research, a large private sector, and so forth. What is frequently missed in this approach is the exceptional societal support the United States has been able to generate for education-particularly in general and higher education. The United States has achieved this model, first through a comprehensive system of secondary education that provides graduates with aspirations and expectations for more education and, second, through a relatively open and comprehensive higher education system. This has led to the belief in American society that the university, particularly the super research university, is not an elitist or esoteric enterprise but rather a remarkably democratic and useful institution. The fact that so many Americans attend and have deep connections to institutions of higher edu- 
cation in all of their many types translates into wide societal support for the costs of super research universities, even if only a small proportion of Americans attend one of the highly selective research institutions.

The super research university model is an expensive one to pursue, requiring a wealthy society. Private money now makes up substantial funding in the United States. Many super research universities are privately controlled. While these factors certainly have enhanced the development of the super research university model, they are not its root cause. Instead, the origin of the super research university is related to how American society has generated widespread societal support for higher education, and included in this are elite research universities. In other words, formal education in the United States has been an early leader in the movement toward mass higher education and all the factors that such an idea includes. Instead of assuming that mass access to higher education and the model of the super research university are mutually exclusive zero-sum forces, what the American case illustrates is that in reality these two trends support one another.

\section{Professors of Practice and the Entrepreneurial University Henry Etzkowitz and James Dzisah}

Henry Etzkowitz is professor and chair of the Management of Innovation, Creativity and Enterprise and the director of the Triple Helix Research Group at the Business School, Newcastle University. He is cooriginator of the "Triple Helix model of University-Industry-Government interactions" and cofounder of the Triple Helix International Conference Series (www.triplehelix6.com).E-mail: henry.etzkowitz@ncl.ac.uk.James Dzisah is a research associate in the Management of Innovation, Creativity and Enterprise and working within the Triple Helix Research Group at the Newcastle University Business School, United Kingdom. E-mail: j.s.dzisah@ncl.ac.uk.

$\mathrm{T}$ he university is undergoing a cultural transformation to play a significant role in knowledge-based society. Universities have different missions. The teaching university is based on education and dedication to human capital development. The research university combines production of knowledge with teaching in a creative tension that has proven more productive than separating these activities. The entrepreneurial university encompasses teaching, research, and service for society. In the course of the "second academic revolution," following the academic revolution that integrated research with teaching, the university is raising economic and social development, its third mission, to the same level as its previous missions.

Entrepreneurial universities have arisen from strikingly different academic foundations, with the first revolution, research, at times occurring simultaneously with the second revolution of economic and social development. An entrepreneurial mode is typically an overlay on a research university, but it can also be a strategy for development from a teaching

Infused with entrepreneurial attitudes and strategic vision, the university collaborates with other actors to bridge the gap between discovery and application.

university, with the phases accomplished simultaneously or even in reverse order to the usual progression. For example, the State University of Rio de Janeiro Friburgo campus began with a PhD program in information technology, accompanied by an incubator, in an innovative academic and regional development strategy.

Infused with entrepreneurial attitudes and strategic vision, the university collaborates with other actors to bridge the gap between discovery and application. In fact, university-industry interaction is often conducted across boundaries, utilizing a variety of linkage mechanisms and arms-length relationships. However, traditional modes of university-industry relations, such as a lump sum payment in exchange for first review of intellectual property rights (e.g., Novartis/Scripps) are problematic due to the tendency for company priorities to shift and the early-stage nature of academic findings with commercial potential that typically requires a translational research process. As a way to address these problems, some universities have utilized the concept of "Professors of Practice" to enhance the academic spin-off process.

\section{Professor of Practice}

Founded in the mid-Igth century, the Massachusetts Institute of Technology (MIT) was the first entrepreneurial university. For its development it drew upon various streams of academic formats invented in or imported to the United States during the early and mid-Igth century for the purpose of establishing a close relationship between the university, technology, and the economy, initially in agriculture and then in industry. During the late I9th century, when MIT was an engineering teaching college, independent consulting engineers were invited into the university as professors to jump-start research.

A similar phenomenon may be currently identified in universities that are utilizing a "Professor of Practice" (PoP) model to further the mission of economic and social development. Typically, the model is a distinguished practitioner who is invited into the university. A PoP with a half-time appointment in 